\title{
МЕТОДОЛОГИЧЕСКИЕ ОСНОВЫ ВНЕДРЕНИЯ ИНТРАПРЕНЕРСТВА С ИСПОЛЬЗОВАНИЕМ ВНУТРЕННИХ ВЕНЧУРНЫХ СТРАТЕГИЙ В ОРГАНИЗАЦИИ
}

\author{
Г. В. Гусева \\ Байкальский государственный университет, г. Иркутск, Российская Федерация
}

\author{
Информация о статье \\ Дата поступления \\ 6 сентября 2017 г. \\ Дата принятия к печати \\ 28 февраля 2018 г. \\ Дата онлайн-размещения \\ 30 марта 2018 г. \\ Ключевые слова \\ Интрапренерство; \\ крупный бизнес; малый \\ бизнес; межфирменное \\ предпринимательство; \\ венчуры; стратегия
}

\begin{abstract}
Аннотация
На сегодняшний день в России особую значимость приобретает процесс развития предпринимательства. В статье исследуется такая форма взаимодействия крупного и малого бизнеса, как интрапренерство. Рассматриваются методологические основы внедрения интрапренерства в организации. Обосновывается необходимость развития интрапренерства в российских компаниях на индивидуально-личностном, групповом и стратегическом уровнях. Анализируются обстоятельства, необходимые для внедрения интрапренерства на индивидуально-личностном уровне. Характеризуются организационные изменения, способствующие внедрению интрапренерства на групповом уровне. Обосновывается целесообразность создания внутренних венчуров и применения внутренних венчурных стратегий. Так, на стратегическом уровне изучаются процессы, влияющие на формирование обновленной бизнес-модели организации. Особое внимание уделяется внутренним венчурным стратегиям корпорации, связанным с внутрифрирменным предпринимательством - интрапренерством, в том числе стратегиям создания внутренних венчуров. Объединение возможностей малого и крупного бизнеса обеспечивает эфффективное функционирование экономики.
\end{abstract}

\section{METHODOLOGICAL BASIS FOR INTRAPRENEURSHIP IMPLEMENTATION WITH THE USE OF INTERNAL VENTURE STRATEGIES IN COMPANIES}

\author{
Galina V. Guseva \\ Baikal State University, Irkutsk, the Russian Federation
}

Article info

Received

September 6, 2017

Accepted

February 28, 2018

Available online

March 30, 2018

\section{Keywords}

Intrapreneurship; large business; small business; intercompany entrepreneurship; ventures; strategy

\begin{abstract}
The process of development of entrepreneurship acquires special significance in today's Russia. The article examines such form of interaction between large and small businesses as intrapreneurship. Methodological foundations for intrapreneurship implementation in an enterprise are considered. The author grounds the necessity of intrapreneurship development in Russian companies at individual, group and strategic levels; determines conditions needed for intrapreneurship implementation at individual level, analyzes organizational changes needed for group intrapreneurship implementation, and proves feasibility of creating internal ventures and the application of internal venture strategies is substantiated. Special attention is paid to internal venture strategies of a corporation, related to intra-firm entrepreneurship - intrapreneurship, including the strategies for creating internal ventures. The integration of small and large business capabilities ensures efficient functioning of the economy.
\end{abstract}

Важным условием устойчивого развития современной экономической системы России является грамотное использование принципов предпринимательской экономики. Отметим, что субъекты малого и среднего бизнеса на сегодняшний день продолжают испытывать определенные трудности в сорере производства. Двойственность экономической приро- 
ды малых и средних компаний проявляется в их мобильности и гибкости, с одной стороны, и в небольшом запасе прочности и маломощности - с другой. Это говорит о более сложных условиях функционирования малого и среднего бизнеса по сравнению с крупными фрирмами [1]. Решению некоторых проблем субъектов малого и среднего бизнеса в состоянии помочь, на наш взгляд, именно крупные предприятия, способные выступать по отношению к малым формам хозяйствования в роли стратегических партнеров [2, с. 96]. Так, одним из принципов предпринимательской экономики, необходимых для ее стабильного роста, является эфффективное взаимодействие крупного и малого бизнеса.

Для описания новых принципов функционирования современной конкурентной экономики Д. Дж. Тис предложил использовать термин «управленческий предпринимательский капитализм», который означает, что деятельность мелких и крупных фрирм должна основываться на распознавании тенденций, размещении и создании новых комбинаций ресурсов для их реализации, трансформации внутреннего организационного механизма для соответствия нововведениям [3]. Из данного утверждения следует, что в современных условиях деятельность малых и крупных компаний без взаимоподдержки и грамотного подхода к управлению ими фактически невозможна.

Инновационный путь развития российских предприятий предполагает поиск наиболее актуальных подходов к реализации инновационного научно-технического потенциала. На сегодняшний день в мировой и российской экономике признается необходимость развития инновационного предпринимательства [4, с. 27]. Так, в современных реалиях в качестве одного из путей повышения инновационной активности предприятий, а также как способ внутреннего роста и развития можно рассматривать внедрение интрапренерства с использованием внутренних венчурных стратегий.

Интрапренерство как способ реализации «управленческого предпринимательского капитализма» дает организации ряд преимуществ за счет активации творческого потенциала сотрудников, существенного повышения эффективности использования ресурсов предприятия, быстрой реакции на изменения потребностей рынка, реализации различных нововведений. Интрапренерство способствует раскрытию стратегических, технологических и финансовых возможностей компании.

Стратегические преимущества находят отражение в расширении клиентуры, освоении новых рынков, в результате чего транс- формируется бизнес-модель организации. Технологические преимущества отражаются в усовершенствовании технологии производства, появлении новых продуктов в результате разработки и внедрения инноваций, финансовые преимущества - в увеличении прибыли, введении в экономический оборот ранее не использовавшихся ресурсов организации и др.

В целях приобретения данных преимуществ компаниям необходимо использование определенного механизма внедрения интрапренерства. Ряд ученых предлагают некоторые модели и принципы, благодаря которым переход к идеям интрапренерства в компании должен осуществляться без сложностей. Рассмотрим некоторые из них.

Л. И. Скибицкая определяет следующие главные принципы построения интрапренерской организации:

- обеспечивать работникам защиту прав собственности на их изобретения внутри организации;

- давать интрапренерским командам ответственность за их средства, даже если они субсидируются из бюджета организации рассматривайте их как центр прибыли, а не затрат;

- проводить усиленные тренировки и обучение, чтобы работники могли развиваться параллельно с организацией;

- требовать от всех правдивости и честности, обратной связи с рынком и поддерживать принятие решений самими сотрудниками;

- создавать внутренний «банковский счет» для каждого внутреннего предприятия;

- рационализировать системы регистрации внутренних фрирм для того, чтобы они остались внутри предприятия;

- создавать систему регистрации договоренностей и договоров (контрактов) между внутренними предприятиями;

- позволять разнообразие в персонале, видах работ, инновационных попытках, изменениях и обменах;

- создавать справедливую систему судейства разногласий между внутренними предприятиями, между сотрудниками и внутренними предприятиями [5].

Модель внедрения интрапренерства, предложенная О. В. Чистяковой, состоит из восьми этапов и предполагает прежде всего осознание необходимости перехода к интрапренерству со стороны руководства, формирование аппарата преобразований, формулирование стратегического видения, целей и стратегий их достижения, ознакомление сотрудников организации со смыслом происходящих перемен. Далее предлагается выявить несоответствия 
между сконструированным желаемым образом организации и ее текущим состоянием и разработать комплекс прогрессивных мероприятий, необходимых для внедрения интрапренерства и соответствующих нововведений в управлении, а также устранить барьеры, препятствующие внедрению интрапренерства, и закрепить новую организационную культуру в декларациях, меморандумах, стандартах предприятия и т. д.

Развивать интрапренерство на российских предприятиях О. В. Чистякова предлагает на трех уровнях - индивидуально-личностном, групповом и стратегическом.

На индивидуально-личностном уровне предлагается создавать условия для формирования инноваторов-интрапренеров, способных создавать и реализовывать собственные проекты.

Несмотря на разносторонний характер работы и широкий круг обязанностей, на малом предприятии специалист практически не имеет возможности профессионально совершенствоваться, у него нет перспектив карьерного роста и систематического повышения квалификации. Однако при оптимальном использовании человеческих ресурсов успешно реализуются цели любого предприятия [6]. Так, именно интрапренерство способствует минимизации ограничений, фрормируемых в рамках работы на малом предприятии, обеспечивая работникам перспективы развития. Также на индивидуальном уровне интрапренерство может быть реализовано путем использования потенциала работников организации в освоении инноваций, обеспечения возможности занимать должности в основной организации и предпринимательском подразделении, а также с учетом развития предпринимательской восприимчивости внутриорганизационной среды. Отметим, что идеи интрапренерства подразумевают, что каждый работник, представляющий собой квалифицированного специалиста, всегда должен цениться руководством. Руководство, в свою очередь, должно обеспечивать персоналу оптимальные качественные условия работы и взаимодействия как в коллективе, так и между сотрудниками и руководством [7, с. 97]. Так, действие принципа уважения должно распространяться не только на работников внутри компании, но и на формирование «поддерживающих взаимоотношений», обеспечение открытости с внешними контрагентами компании, что положительным образом скажется на бизнесе [8, с. 71].

На групповом уровне необходимо создание климата, способствующего генера- ции идей и обмену ими между сотрудниками. Особый интерес при этом представляют корпоративные венчуры - создаваемые отдельные организационные структуры для реализации рискованных идей и доведения их до коммерческого воплощения.

Интрапренерство на групповом уровне реализуется формированием групп для решения проблем, а также созданием венчуров и независимых хозяйственных единиц.

Как альтернатива этому процессу может рассматриваться сотрудничество крупных предприятий с малыми инновационными предприятиями, которые берут исследовательские рисковые проекты на аутсорсинг или же самостоятельно развивают инновационные проекты и передают их в дальнейшем корпорации на доводку и коммерческую реализацию.

На стратегическом уровне внедрение интрапренерства позволяет пересматривать бизнес-модель организации, развивать ее, включая новые инновационные направления. При этом первоначально инновационные проекты следует внедрять наряду с традиционным производством. Впоследствии они могут постепенно заместить традиционное производство или сосуществовать с ним в определенных пропорциях в соответствии с требованиями рынка.

В современных условиях создание управленческих стратегий в компаниях, представляющих собой малые фрормы хозяйствования, реализуется с учетом большого количества трудностей, являющихся специфическими для российской экономики. В таких непростых условиях для успешной и грамотной реализации выбранной компанией стратегии необходима разработка и введение в действие механизма реализации стратегии развития компании [9]. Интрапренерство на стратегическом уровне реализуется посредством изменения бизнес-модели организации за счет внедрения новых разработок и необходимости учета влияния модели роста на бизнес-модель организации, а также с учетом формирования бизнес-модели снизу вверх и сверху вниз. Успех бизнеса возможен при непрерывной оценке потенциала организации и возможностей ее внешней среды и дальнейшей трансформации этих возможностей в собственные ресурсы [10, с. 98].

Таким образом, внедрение в действующей организации интрапренерства позволяет повысить ее конкурентоспособность, что дает ей возможность выйти на качественно новый уровень функционирования, скорректировав бизнес-модель [11, с. 84-85].

Основные этапы внедрения интрапренерства в организации представлены на рис. 1 . 


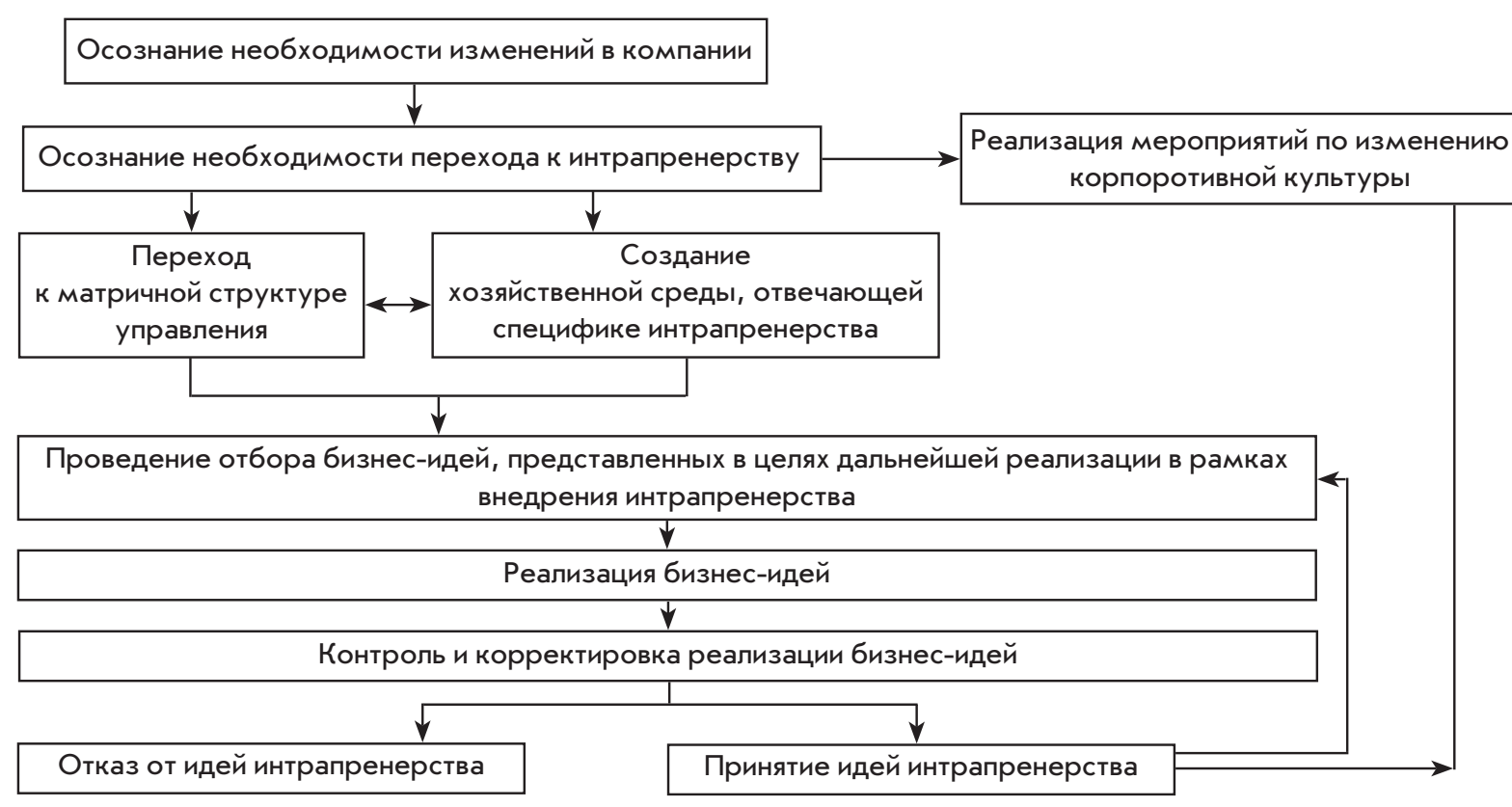

Рис. 1. Модель внедрения системы интрапренерства с использованием внутренних венчурных стратегий в организации

Остановимся подробнее на содержательной стороне каждого этапа становления системы инрапренерства с использованием внутренних венчурных стратегий в организации.

1. Осознание необходимости изменений в компании. Первый этап внедрения системы интрапренерства в организации необходимо начать, на наш взгляд, не с процесса внедрения интрапренерства непосредственно, а с осознания существующих в компании на настоящий момент проблем. Следует изучить сложившуюся в организации хозяйственную среду путем проведения ее объективного анализа, в том числе оценки эфрфективности, конкурентоспособности, способности к развитию. При этом можно использовать различные экономические анализы и инструменты PEST-, SWOT-анализа и др.

Если компанией выявляется необходимость изменений, которые смогут быть реализованы посредством взаимодействия с представителями иной формы бизнеса (малого, среднего или крупного), тогда дальнейшим шагом будет подбор и исключение различных фрорм взаимодействия малого и крупного бизнеса. Необходима грамотная оценка по ряду критериев, например: кадровый потенциал, производственно-техническая деятельность, юридические аспекты, финансово-экономическое состояние, деловая культура в компании и др. Отметим, что в условиях нестабильной хозяйственной среды успешное ее решение во многом зависит от того, насколько менеджеры, помимо знаний методов управления, обладают предпринимательским стилем мышления.

2. Осознание необходимости перехода к интрапренерству. Если в результате проведенного анализа делается вывод, что наиболее рационально создание среды для генерирования, формирования и поддержания инициативных предпринимательских групп, чьи идеи будут наиболее эффрективно реализовываться, то наилучший вариант в данном случае - внедрение интрапренерства.

Нами предлагается рассматривать осуществление внедрения интрапренерства с использованием внутренних венчурных стратегий, так как они наиболее грамотно отражают суть внутрифирменного предпринимательства.

3. Переход к матричной структуре управления организацией. Организация внутреннего венчура наиболее эффрективна в случае, если предприятие имеет матричную организационную структуру. На рис. 2 показана примерная матричная организационная структура предприятия. В таком варианте работники могут быть закреплены за венчурным подразделением в фрорме «невидимого контракта», предполагающего одновременную их занятость в новом подразделении с сохранением должности в основном подразделении предприятия. Отметим, что такие внутренние венчуры должны обладать высокой экономической и хозяйственной автономией. 


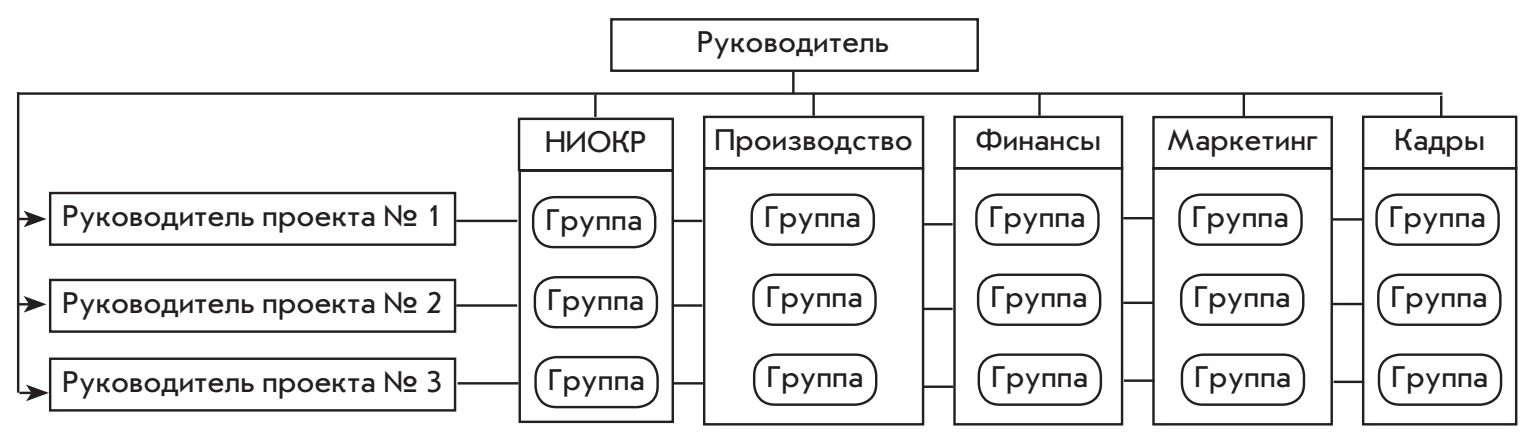

Рис. 2. Матричная организационная структура Источник: [12, с. 4]

Таким образом, очевидно, что для наиболее эффективного внедрения интрапренерства в организации с использованием внутренних венчурных стратегий необходимо перестроить организационную структуру предприятия.

4. Создание хозяйственной среды, отвечающей специфрике интрапренерства. Данный пункт представляет собой ряд мероприятий, включающих в себя работу с сотрудниками компании (индивидуально-личностный уровень), с ресурсами компании и обеспечением необходимых условий труда (групповой уровень), с задачами и целями деятельности компании (стратегический уровень).

Мероприятия, необходимые для грамотного внедрения интрапренерства в компании с использованием внутренних венчурных стратегий, представлены в таблице.
Мероприятия, необходимые для грамотного внедрения интрапренерства

\begin{tabular}{|c|c|}
\hline $\begin{array}{c}\text { Уровень } \\
\text { воздей- } \\
\text { ствия }\end{array}$ & Мероприятия \\
\hline $\begin{array}{l}\text { Индиви- } \\
\text { дуаль- } \\
\text { но-лич- } \\
\text { ностный } \\
\text { уровень }\end{array}$ & $\begin{array}{l}\text { Формирование аппарата преобразований. } \\
\text { Достижение понимания необходимости } \\
\text { перехода к интрапренерству со стороны } \\
\text { руководства, высшего и среднего звеньев } \\
\text { управления. } \\
\text { Обеспечение сотрудников ресурсами, } \\
\text { необходимыми для преобразований } \\
\text { (рабочая атмосфрера; время, отводимое } \\
\text { непосредственно на разработки; денеж- } \\
\text { ные средства и др.) }\end{array}$ \\
\hline $\begin{array}{l}\text { Груп- } \\
\text { повой } \\
\text { уровень }\end{array}$ & $\begin{array}{l}\text { Формирование команды интрапрене- } \\
\text { ров - сильной группы единомышленников } \\
\text { и вдохновителей. } \\
\text { Создание внутреннего венчура в организа- } \\
\text { ции группой единомышленников }\end{array}$ \\
\hline $\begin{array}{l}\text { Страте- } \\
\text { гический } \\
\text { уровень }\end{array}$ & $\begin{array}{l}\text { Изменение бизнес-модели организации за } \\
\text { счет внедрения новых идей и разработок. } \\
\text { Формирование стратегического видения, } \\
\text { целей и стратегий их достижения. } \\
\text { формирование желаемого образа } \\
\text { компании в перспективе. } \\
\text { Доведение руководством разработанной } \\
\text { стратегии и видения смысла происходя- } \\
\text { щих перемен до сотрудников. } \\
\text { Создание и поддержание в организации } \\
\text { духа интрапренерства }\end{array}$ \\
\hline
\end{tabular}

5. Отбор бизнес-идей, представленных в целях дальнейшей реализации в рамках внедрения интрапренерства в компании. В период осуществления мероприятий, необходимых для грамотного внедрения интрапренерства в компании с использованием внутренних венчурных стратегий, а также на протяжении специально отведенного времени после проведения мероприятий инициативные сотрудники-интапренеры или группы сотрудников-интрапренеров организации предоставляют бизнес-идеи независимой группе специалистов компании. На основании ряда критериев производится отбор для реализации лучших проектов.

Обозначим шесть критериев, по которым, на наш взгляд, следует анализировать и отбирать бизнес-идеи:

- материальное обеспечение (какие материалы, сырье, оборудование, производственные площади потребуются для реализации проекта);

- первоначальный капитал (размер инвестиций, необходимых для реализации проекта, и возможность изыскания средств);

- персонал (сколько и какой квалификации сотрудников потребуется привлечь для реализации проекта, степень готовности и мотивации сотрудников);

- проведение предпринимательских расчетов с целью выявления возможного эффректа (длительность подготовительного периода и срок оборачиваемости капитала);

- возможная реакция потребителя;

- прогноз перенесения идеи в практическую плоскость с учетом ситуации на рынке.

Таким образом, после качественного отбора и осуществления экспертной оценки полученной информации о результатах предпринимательских расчетов, проводимых группой специалистов, выявляются проекты, наиболее соответствующие идеям интрапренерства и внутренним венчурным стратегиям организации. 
6. Реализация бизнес-идей, наиболее подходящих деятельности компании в форме новых инновационных подразделений (внутренних венчуров). Определим несколько этапов реализации принятой бизнес-идеи, осуществляемой с целью внедрения интрапренерства в организации':

- Бизнес-планирование, суть которого заключается в детальном изложении реализации проекта. Также в бизнес-плане указывается организационная форма предпринимательства, источники формирования денежных средств, необходимых для начального этапа воплощения идеи, расчеты ожидаемых результатов от реализации проекта, потенциальные риски и др. Данный этап реализуется в рамках отбора бизнес-идей, представленных в целях дальнейшей их реализации в рамках внедрения интрапренерства в компании.

- Организационно-техническая подготовка формы к реализации проекта производится непосредственно после выбора бизнес-идеи и включает три части: организационную подготовку; техническую подготовку; технологическую подготовку. Организационная подготовка подразумевает следующие стадии: разработку проекта организации основного производственного процесса; разработку проекта технологического обслуживания основного производства; разработку системы организации и оплаты труда; организацию материально-технического обеспечения производства и сбыта новой продукции; создание нормативной базы для внутризаводского технико-экономического и оперативно-производственного планирования. К технической подготовке относятся работы по приспособлению и обустройству рабочей обстановки и территории. Технологическая подготовка включает подготовку строительных машин, комплектование их сменным оборудованием, оснасткой и т. д.

Так как внутрифирменное предпринимательство осуществляется в рамках уже существующего предприятия, организационно-техническая подготовка фрирмы к реализации проекта существенно упрощается, поскольку организационно-техническая база компании позволяет изыскать возможности, необходимые для реализации проектов сотрудников-интрапренеров, без существенных вложений.

- Руководство функционирующим проектом и связями проекта интрапренеров с

1 Предпринимательская идея иее выбор. URL: http: / / www.up2go.ru/published/beginning-businessman/ 716.htm. основной управляющей структурой компании. Управление проектом осуществляется непосредственно группой интрапренеров, предложивших бизнес-идею. Определяемый внутри данной группы руководитель проекта в установленном порядке предоставляет отчетность руководству организации. Так осуществляется связь интрапренеров, реализующих свой венчурый проект, с основной управляющей структурой компании.

7. Контроль и корректировка реализации бизнес-идей в рамках внедрения интрапренерства с использованием внутренних венчурных стратегий. Контроль за реализацией проекта осуществляет руководство организации за счет отчетности, предоставляемой группой интрапренеров.

В процессе реализации проекта руководство организации производит оценку, результатом которой является выявление несоответствия между сконструированным желаемым образом организации, внедрившей интрапренерство посредством внутренних венчурных стратегий, и ее текущим состоянием. В случае наличия несоответствия ожиданий и реальной ситуации производится корректировка реализации бизнес-идей совместными усилиями руководителей организации и интрапренеров.

8. Отказ от идей интрапренерства/ принятие идей интрапренерства. Так, по результатам реализации проекта интрапренерами компании организация принимает решение, отказаться ли от идей интрапренерства или принять данную стратегию с проведением дальнейших мероприятий по поддержанию новой предпринимательской среды внутри компании. В случае принятия идей интрапренерства в компании происходит закрепление новой организационной культуры как на нормативном уровне, так и на уровне внутрифирменного менталитета.

Параллельно с внедрением интрапренерства на уровне принятия и реализации бизнес-идей требуется проведение мероприятий по изменению корпоративной культуры. Необходимо осуществление комплекса прогрессивных мероприятий с целью повсеместного внедрения интрапренерства в организации.

Так, с момента начала реализации программы внедрения интрапренерства в компании и на протяжении ее дальнейшего существования интрапренеры компании должны ощущать полную поддержку со стороны высшего руководства, должны быть оперативно обеспечены всеми необходимыми финансовыми, трудовыми и иными ресурсами, 
а руководство компании должно быть всесторонне заинтересовано в реализации программы интрапренерства, должно разрабатывать соответствующую систему мотивации сотрудников и неизменно источать уверенность в производимых в компании идейных изменениях. Необходимо оценивать успех как всей стратегии перехода на интрапренерство, так и каждого нового внутреннего венчура в частности. Важно помнить, что если организация не вкладывает каптал в долгосрочные венчурные проекты, которые сулят прибыль лишь в отдаленной перспективе, развитие интрапренерства практически невозможно.

\section{СПИСОК ИСПОЛЬЗОВАННОЙ ЛИТЕРАТУРЫ}

1. Гончарова Н. А. Современные тенденции в развитии малого и среднего бизнеса / Н. А. Гончарова, Е. А. Сладкова // Труды Братского государственного университета. Сер.: Экономика и управление. 2015. - T. 1. - C. 88-91.

2. Набиев Р. А. Развитие систем взаимодействия малого и крупного предпринимательства / Р. А. Набиев, Г. А. Тактаров / / Вестник Астраханского государственного технического университета. Сер.: Экономика. 2011. - № 2. - С. 95-100.

3. Тис Д. Дж. К экономической теории многопродуктовой фирмы / Д. Дж. Тис // Вестник Санкт-Петербургского университета. Сер. 8, Менеджмент. - 2005. - Вып. 3. - С. 3-38.

4. Самаруха В. И. Проблемы формирования институциональной сфреры и инновационной инфраструктуры в Сибирском фредеральном округе, в целях устойчивого социально-экономического развития его регионов / В. И. Самаруха / / Научный вестник Байкальского государственного университета экономики и права. 2015. - № 2 (26). - С. 24-33.

5. Скибицкая Л. И. Организация труда менеджера [Электронный ресурс] / Л. И. Скибицкая. - Режим доступа: http://studbooks.net/25676/menedzhment/intraprenerski_komandnye_struktury.

6. Ходакова Н. Н. Организация привлечения персонала в малые предприятия и инструменты кадровой работы / Н. Н. Ходакова / / Управление экономическими системами : электрон. науч. журн. - 2011. — № 36. C. 53. - Режим доступа: http://uecs.ru/otraslevaya-ekonomika/item/825-2011-12-01-06-45-50.

7. Краснобаева А. Современный менеджмент в структурах малого бизнеса / А. Краснобаева, С. Матинян // Актуальные вопросы инновационной экономики. - 2014. - № 7. - С. 92-97.

8. Вепрова Р. Н. Управление производственными процессами как фактор развития компании / Р.Н. Вепрова // Экономика и управление: проблемы, решения. - 2017. - Т. 4, № 7. - С. 67-72.

9. Туренко Б. Г. Комплексная стратегия развития предприятий малого и среднего бизнеса / Б. Г. Туренко, Т. А. Туренко. - Иркутск : Изд-во БГУЭП, 2013. - 224 с.

10. Баева О.Н.Формирование и развитие компетенций стратегического управления / О. Н. Баева // Актуальные тенденции развития мировой экономики : материалы междунар. науч.-практ. конф. : в 2 ч. - Иркутск : Изд-во БГУЭП, 2016. - Ч. 2. - С. 95-99.

11. Чистякова О. В. Инновационные аспекты повышения конкурентоспособности предпринимательских структур / О. В. Чистякова. - Иркутск : Изд-во БГУЭП, 2011. - 204 с.

12. Цыплаков А. А. Организация инновационной деятельности в форме внутреннего венчура [Электронный ресурс] / А. А. Цыплаков, П. В. Смирнова / / Науковедение : интернет-журн. — 2013. — № 6 (19). - Режим доступа: https: / /naukovedenie.ru/index.php?p=issue-6-13-economy-management.

\section{REFERENCES}

1. Goncharova N. A., Sladkova E.A. Modern Trends in the Development of Small and Medium-Size Business. Trudy Bratskogo gosudarstvennogo universiteta. Seriya: Ekonomika i upravlenie = Proceedings of Bratsk State University. Series: Economics and Management, 2015, vol. 1, pp. 88-91. (In Russian).

2. Nabiev R. A., Taktarov G. A. Development of the Systems of Small and Large. Vestnik Astrakhanskogo gosudarstvennogo tekhnicheskogo universiteta. Seriya: Ekonomika = Vestnik of Astrakhan State Technical University. Series: Economics, 2011, no. 2, pp. 95-100. (In Russian).

3. Tis D. Dzh. Towards an Economic Theory of the Multiproduct Firm. Vestnik Sankt-Peterburgskogo universiteta. Seriya 8: Menedzhment = Bulletin of Saint Petersburg University. Series 8: Management, 2005, vol. 3, pp. 3-38. (In Russian).

4. Samarukha V. I. Problems of formation of institutional environment and innovation infrastructure in the Siberian Federal District for sustainable socioeconomic development of its regions. Nauchnyi vestnik Baikal'skogo gosudarstvennogo universiteta ekonomiki i prava = Scientific Bulletin of Baikal State University of Economics and Law, 2015, no. 2 (26), pp. 24-33. (In Russian).

5. Skibitskaya L. I. Organizatsiya truda menedzhera [Organization of Labour of a Manager]. Available at: http: // studbooks.net/25676/menedzhment/intraprenerski_komandnye_struktury. (In Russian).

6. Khodakova N. N. Arrangement of the personnel involvement into small companies, and mechanisms of personnel management. Upravlenie ekonomicheskimi sistemami = Management of economic systems, 2011, no. 36, pp. 53. Available at: http://uecs.ru/otraslevaya-ekonomika/item/825-2011-12-01-06-45-50. (In Russian).

7. Krasnobaeva A., Matinyan S. Modern Management in Small Business Structures. Aktual'nye voprosy innovatsionnoi ekonomiki = Topical Issues of Innovative Economy, 2014, no. 7, pp. 92-97. (In Russian).

8. Veprova R. N. Management of production processes as a factor of company development. Ekonomika i upravlenie: problemy, resheniya = Economics and Management: Problems and Solutions, 2017, vol. 4, no. 7, pp. 67-72. (In Russian). 
9. Turenko B. G., Turenko T. A. Kompleksnaya strategiya razvitiya predpriyatii malogo i srednego biznesa [Comprehensive Strategy of Development of Small and Medium-Sized Business]. Irkutsk, Baikal State University Publ., 2013. $224 \mathrm{p}$.

10. Baeva O. N. The formation and development of competencies of strategic management. Aktual'nye tendentsii razvitiya mirovoi ekonomiki. Materialy mezhdunarodnoi nauchno-prakticheskoi konferentsii [Current Trends in the Development of World Economy. Materials of International Research Conference]. Irkutsk, Baikal State University Publ., 2016, vol. 2, pp. 95-99. (In Russian).

11. Chistyakova O. V. Innovatsionnye aspekty povysheniya konkurentosposobnosti predprinimatel'skikh struktur [Innovation aspects of improving business competitiveness]. Irkutsk, Baikal State University Publ., 2011. 204 p.

12. Tsyplakov A., Smirnova P. The organization of innovation in the form of internal ventures. Naukovedenie = Science Studies, 2013, no. 6 (19). Available at: https://naukovedenie.ru/index.php?p=issue-6-13-economy-management. (In Russian).

\section{Информация об авторе}

Гусева Галина Викторовна - старший преподаватель, кафедра теории государства и права и социально-правовых дисциплин, Байкальский государственный университет, 664003, г. Иркутск, ул. Ленина, 11, e-mail: galiguseva@yandex.ru.

\section{Для цитирования}

Гусева Г. В. Методологические основы внедрения интрапренерства с использованием внутренних венчурных стратегий в организации / Г.В.Гусева // Известия Байкальского государственного университета. - 2018. - T. 28, № 1. - C. 36-43. - DOI: $10.17150 / 2500-2759.2018 .28(1) .36-43$.

\section{Author}

Galina V. Guseva - Senior Lecturer, Department of Theory of State and Law and Socio-Legal Disciplines, Baikal State University, 11 Lenin St. , 664003, Irkutsk, the Russian Federation, e-mail: galiguseva@yandex.ru.

\section{For citation}

Guseva G. V. Methodological Basis for Intrapreneurship Implementation with the Use of Internal Venture Strategies in Companies. Izvestiya Baykal'skogo gosudarstvennogo universiteta = Bulletin of Baikal State University, 2018, vol. 28, no. 1, pp. 36-43. DOI: 10.17150/2500-2759.2018.28(1).3643. (In Russian). 